\title{
Habermas and information systems research: New directions
}

\author{
Alain Ross $^{\mathrm{a}, *}$, Mike Chiasson ${ }^{\mathrm{b}, 1}$ \\ a Athabasca University, 1 University Drive, Athabasca, Alberta, Canada, T9S 3A3 \\ b Management School, Lancaster University, Lancaster LA1 4YX, UK
}

\section{A R T I C L E I N F O}

\section{Article history:}

Received 9 June 2010

Received in revised form 7 June 2011

Accepted 7 June 2011

Available online 1 July 2011

\begin{abstract}
A B S T R A C T
Habermas' critical social theory has proven to be an important and useful lens in information systems research, especially in understanding the communicative potential of information systems and in conceiving alternative approaches to information systems development. As communication and engagement have become increasingly important in the context of today's information systems, his work has perhaps even greater applicability. However, concerns that it is too utopian to apply in organizational settings have led to skepticism regarding Habermas' work. Participation by all, the "ideal speech situation" and the consensus ideal are each Habermasian requirements that have sparked this criticism.

However, Habermas' work has continued to grow and evolve since the Theory of Communicative Action, the basis of much IS research drawing on his work. His contributions in discourse ethics $(1990,1993)$ and deliberative democracy (1998) have offered us new and important theory, and have brought to light Habermas' own clarification and evolution of his original ideas.

The intent of this paper is to reopen a communicative dialog about Habermas' work. After summarizing his critical social theory, we turn to addressing our two main objectives: first, to demonstrate that evolutions in Habermasian thought have renewed its empirical possibilities and, second, to show that this new understanding constructively informs future IS research. As an illustration, we sketch out the conditions for a Habermasian-inspired requirements process and show their application to a well-studied IS development model, ETHICS (Mumford, 1983). We conclude by suggesting that Habermas' theoretical ideas can no longer be dismissed as naive, but as a constant guide to critical action - as a reference point for opening up new possibilities for communicative action in IS research and activity.
\end{abstract}

(C) 2011 Elsevier Ltd. All rights reserved.

* Corresponding author. Tel.: +1 4032578061.

E-mail addresses: alainr@athabascau.ca (A. Ross), m.chiasson@lancaster.ac.uk (M. Chiasson).

1 Tel.: + 441524594255 . 


\section{Introduction}

Habermas' critical social theory has proven to be an important and useful lens in information systems research. IS researchers have investigated e-mail use (Ngwenyama \& Lee, 1997), information systems and information technology (Cukier, Ngwenyama, Bauer, \& Middleton, 2009; Hirschheim, Klein, \& Lyytinen, 1996), information systems development and its methods (Auramäki, Lehtinen, \& Lyytinen, 1988; Hirschheim \& Klein, 1994; Janson, Woo, \& Smith, 1993), and systems implementation (Myers \& Young, 1997) through the lens of Habermas' Theory of Communicative Action. These studies have provided new insights into these respective phenomena of interest; some are considered seminal works in the IS field.

Today's information systems context, which includes the emergence of systems that are fundamentally about communication, collaboration and engagement, gives Habermas' work even greater relevance and applicability. Web 2.0 tools such as wikis and social networking provide communicative opportunities that extend from supporting open dialog to allowing the creation of solutions to complex problems through the leveraging of multiple voices (so-called "crowdsourcing") (Doan, Ramakrishnan, \& Halevy, 2011; Hansen, Berente, \& Lyytinen, 2009). e-Government systems seek to engage in more complete citizen participation (Olphert \& Damodaran, 2007). Community-based information systems are employed within broader efforts to engage community participation within development programs (Parmar, Keyson, \& de Bont, 2009; Puri, Sahay, \& Lewis, 2009). These systems, like many others that are typical of today's information systems context, focus our attention on the extent to which they meet these communicative and democratic objectives (Hansen et al., 2009; Mingers \& Walsham, 2010). Further, to meet these objectives, the creators of these systems often seek to engage broad-based participation in their development. Habermas' theories on communication, discourse and democracy provide important perspectives within which these questions can be considered.

While some researchers have embraced Habermas' work, others appear to be pessimistic towards the usefulness of Habermas' theoretical lens. This pessimism makes itself known anecdotally - in discussions with colleagues, in reviews of Habermasian-based work, and during public discussions at conferences. It is also expressed in research articles which critique his work (c.f. Adam, 2002; Brooke, 2002). In particular, Habermas' theory, with its focus on the ideal speech situation, consensus and participation by all, has been seen to be overly utopian and therefore irrelevant in many organizational environments.

However, most IS research that has drawn upon Habermas' work has been based on his Theory of Communicative Action published in English in 1984 (Volume 1) and 1987 (Volume 2), or his earlier discussion of knowledge interests (Habermas, 1971). Yet Habermas' work has continued to grow and evolve since that time. Of particular note are his works on discourse ethics (1990, 1993) and deliberative democracy (1998), which he has applied to medical ethics (Habermas, 2003), terrorism (Borradori, 2003) and law (Habermas, 1998). Not only have these works offered us new and important theory, they have illustrated clarifications and an evolution of his original theory.

The purpose of this paper is two-fold. First, we explore Habermas' more recent work to demonstrate that, while unabashedly utopian, Habermas' work is more amenable to practical application than his critics have allowed. Second, we discuss how the clarifications and evolution revealed in this new work have important implications for IS researchers and practitioners. Certainly, a clear understanding of how his theories have evolved is critical to ensuring a thoughtful and nuanced appropriation of his work and to the further use of his ideas in IS research. Beyond this, a new understanding of Habermas' theory opens up opportunities to design and develop more democratic IS processes and technologies in organizations.

To reopen a communicative dialog about Habermas' work, this paper briefly revisits his Theory of Communicative Action before turning to a discussion of his most recent work - especially his work on discourse ethics and deliberative democracy. We then explore three specific clarifications in his work - in the "ideal speech situation", the consensus ideal and participation by all - and explore the implications of these to IS research and practice. As an illustration, we sketch out the conditions for a Habermasianinspired requirements determination process. 


\section{Habermas' critical social theory}

\subsection{The theory of communicative action $\left(1984,1987^{2}\right)$}

The Theory of Communication Action (Habermas, 1984, 1987) is not Habermas' first work but is certainly considered one of his most important. In it, he addresses three main concerns:

1. to develop a concept of rationality that is no longer tied to, and limited by, the subjectivistic and individualistic premises of modern philosophy and social theory,

2. to construct a two-level concept of society that integrates the lifeworld and system paradigms, and

3. to sketch out, against this background, a critical theory of modernity which analyzes and accounts for its pathologies in a way that suggests a redirection rather than an abandonment of the project of enlightenment (McCarthy, 1984: vi).

That is, Habermas wants to build a theory of society that remains grounded in a concept of rationality, but a rationality that depends upon neither an "ultimate foundation" (Habermas, 1984: 2) like religion or philosophy nor on the knowing subject capable of using that knowledge to achieve specific ends. Habermas instead seeks a concept of rationality as intersubjectively defined through communication, or what he calls communicative rationality.

To do this, Habermas builds on the speech act theory contributions of both Austin (1962) and Searle (1969) in first developing his concept of communicative action (Habermas, 1984). He arrives at a definition of communicative action as "linguistically mediated interactions in which all participants pursue illocutionary aims, and only illocutionary aims, with their mediating actions of communication" (Habermas, 1984: 295, emphasis in the original). For Habermas, illocutionary aims are those in which the speaker's intent is to perform an action through his or her words. The speaker reveals, expresses, asserts or commits during speech, and through these types of utterances, takes on a form of social action.

Habermas contrasts communicative action with strategic action (Habermas, 1984). Strategic action is interaction where the speaker has perlocutionary aims (i.e., intentions to produce some effect upon the hearer). Strategic action is broken down into open strategic action and latent (hidden) strategic action. Further discrimination is made between latent strategic action in which the speaker is aware of his deception - that is, manipulation - and latent strategic action in which the speaker is unaware of his deception - that is, systematically distorted communication.

The distinction between communicative and strategic action is critical in Habermas' theory. Strategic action is oriented toward success - that is, the speaker is oriented toward achieving her/his goals or objectives. Communicative action is oriented toward mutual understanding; while the speaker still has her/his own objectives and goals, these are held in check, in favor of reaching an intersubjective understanding with the hearer. It is important to avoid seeing one or the other forms of interaction as universally better than the other. In certain circumstances, strategic action (of the open variety) is expected and desirable. However, the two forms of interaction cannot coexist; that is, it is impossible to work toward mutual understanding and coordination of action without setting aside (as much as possible) the goal of reaching one's own objectives and interests. In this way, Habermas (1984) says that strategic action is "parasitic" (p. 288) upon communicative action.

Communicative action, then, lays a foundation for "a consensual coordination of individually pursued plans of action" (Habermas, 1984: 295-6). For an interaction to be able to support this coordination, however, Habermas suggests general conditions that must be satisfied - comprehensibility of the utterance, acceptance of the guarantees implicit within the speech act, and acceptance of the obligations arising from the interaction (Habermas, 1984).

The condition of comprehensibility means that the hearer must understand the speaker's communication - that is, the hearer must understand the meaning of what is being said. This level of understanding is, however, weak. Understanding in a stronger sense requires knowledge of the conditions that make the speech act "acceptable" to the hearer. Therefore, comprehensibility is simply a necessary prerequisite to more complete understanding.

\footnotetext{
${ }^{2}$ Note that the years provided here are the years of the English translations of these works. Theory of Communicative Action was first published in German in 1981.
} 
Table 1

Habermas' validity claims.

\begin{tabular}{|c|c|c|c|}
\hline $\begin{array}{l}\text { Validity } \\
\text { claim }\end{array}$ & Worldview & $\begin{array}{l}\text { Speech act in which this is the primary } \\
\text { validity claim }\end{array}$ & Example \\
\hline Truth & $\begin{array}{l}\text { "The" } \\
\text { world }\end{array}$ & Constantive & "The current information system is slow." \\
\hline $\begin{array}{r}\text { Truthfulness } \\
\text { (sincerity) }\end{array}$ & $\begin{array}{l}\text { "My" } \\
\text { world }\end{array}$ & Expressive & $\begin{array}{l}\text { "I dislike the way in which error messages are } \\
\text { displayed." }\end{array}$ \\
\hline $\begin{array}{l}\text { Legitimacy } \\
\quad \text { (rightness) }\end{array}$ & $\begin{array}{l}\text { "Our" } \\
\text { world }\end{array}$ & Regulative & $\begin{array}{l}\text { "I promise to implement the re-ordering process in the } \\
\text { new software." }\end{array}$ \\
\hline
\end{tabular}

The next general condition toward acceptability is the acceptance of the guarantees made in the speech act. Habermas (1984) calls these guarantees validity claims and suggests that there are three ${ }^{3}-$ truthfulness, legitimacy and truth. The claim of truthfulness asks whether the speaker is sincere. The claim of legitimacy asks whether the speaker is making a statement that is "right in respect to the given normative context" (Habermas, 1984: 307). The claim of truth asks whether the speaker makes true statements and makes correct assumptions.

Habermas (1976) describes these three validity claims as representing and testing utterances within appropriate world-views. The claim to truth makes claims about "'the' world of external nature" (p. 92) (that is, the objective world). The claim to truthfulness makes claims about "'my' world of internal nature" (p. 92) (i.e., the subjective world). The claim to legitimacy makes claims about "'our' world of society" (p. 92) (i.e., the social world). This view of communication - initially termed "universal pragmatics" and later "formal pragmatics" - characterizes speech acts as representing, simultaneously, "the" world, "my" world and "our" world (Habermas, 1976).

In communicative action, all three claims to validity are embedded within each speech act. As outlined in Table 1, Habermas (1984) classifies speech acts based on which validity claim is made "first and foremost" (p. 308). Regardless of which claim is primary, however, the speaker must be prepared to "vindicate" (address) any or all of the validity claims implicit and explicit in her speech act. For Habermas, it is this quality of a speech act that gives it illocutionary force.

The final condition - acceptance of the obligations arising from the interaction - requires speakers to act in accordance with their words. In expressive speech acts (those in which the primary validity claim is sincerity), it is not possible to convince a hearer by giving reasons, that a speaker is being sincere. Instead, the speaker is obligated to act in a way that is consistent with her statements. In order to evaluate the speaker's trustworthiness, the hearer may check the consistency of the speaker's statements with her current and future actions.

These general conditions - comprehensibility of the utterance, acceptance of the guarantees implicit in the communication, and acceptance of the obligation arising from the interaction - are the conditions necessary to judge the acceptability of a speech act. However, when agreement cannot be reached regarding the acceptance of validity claims, participants move to discourse:

Under the heading "action" I introduce that area of communication in which we silently presuppose and recognize implied validity claims in engagements (even in assertions) in order to exchange information (that is, behavior-related experiences). Under the heading "discourse", I introduce the form of communication characterized by argumentation in which validity claims that have become problematic are made the subject of discussion and examined relative to their legitimacy. In order to entertain a discourse, we must in a way step out of behavioral and experiential contexts; here we exchange not information, but rather arguments that serve to establish (or reject) problematic validity claims (Habermas in Horster, 1992: 31).

\footnotetext{
${ }^{3}$ It should be noted that, in earlier works, Habermas posited the existence of four validity claims. The fourth validity claim was comprehensibility (Habermas, 1976). In The Theory of Communicative Action, Habermas suggests comprehensibility is embedded in the speech act itself.
} 
To undertake argumentation, participants must approach each other assuming that all participants are willing to be swayed solely by "the force of the better argument" (Habermas, 1984:24). This means that participants set aside all motives except "the cooperative search for the truth" (ibid). It also means that the context in which argumentation occurs must be absent (or relatively absent) of external forces which distract participants from this search. These conditions characterize what Habermas (at that time) called the "ideal speech situation".

\subsubsection{System and lifeworld}

Having developed his theory of communication action, Habermas' next concerns are to present a two-level concept of society (system and lifeworld) and demonstrate the pathologies that arise when the steering media of the system (money and power) replace and disturb the communicative action in the lifeworld. These concerns are addressed by first understanding that communicative action takes place against the backdrop of the lifeworld - a background of implicit, pre-reflective knowledge (Habermas, 1987). Habermas uses Husserl's definition of lifeworld as consisting of "individual skills, the intuitive knowledge of how one deals with a situation; and from socially acquired practices, the intuitive knowledge of what one can rely on in a situation, not less than, in a trivial sense, the underlying convictions" (Habermas, 1987: 35).

As we have seen, when people fail to reach agreement in communication (that is, when validity claims have become problematic), they move to discourse to re-establish agreement. When the background of knowledge upon which individuals draw is (relatively) shared, the need to move to discourse is less frequently experienced. However, as societies have grown increasingly complex and diverse, Habermas argues that the ability to reach agreement becomes more strained and the need to move communication to the level of discourse becomes more frequent.

As a result, systems have emerged which relieve the necessity of having to reach agreement on every issue. In Theory of Communicative Action, Habermas (1987) identifies two main sub-systems: the economic system and the political system. Unlike subsystems in the lifeworld which are guided through language, these systems are steered by the media of money and power (respectively). Systems are sites of strategic and instrumental action rather than the communicative action that characterizes the lifeworld. Systems serve a useful purpose in society - to diminish the burden of reaching agreement on every issue that becomes problematic in a differentiated and complex society. However, when the media of money and power crowd out language as the medium of the lifeworld (what Habermas calls colonization), societal problems arise. Decolonization, then, is the emancipatory project arising from this Habermasian work. McCarthy (1984) summarizes,

"A communicatively rationalized lifeworld would have to develop institutions out of itself through which to set limits to the inner dynamic of media-steered subsystems and to subordinate them to decisions arrived at in unconstrained communication." (p. xxxvii).

\subsection{Discourse ethics (1990)}

In the Theory of Communicative Action, Habermas proposed a view of society in which individuals create mutual understanding and coordination of action through the force of unconstrained communication. In Moral Consciousness and Communicative Action, Habermas offers discourse ethics, a continuation of this idea.

Discourse ethics is proposed as the procedure for justifying norms - "legitimately ordered interpersonal relations". (Habermas, 1990: 59). That is, discourse ethics considers how best to answer questions of "what should we do". Habermas is concerned with providing a means of justification that leaves "all concrete moral and practical judgments to the participants themselves" (McCarthy, 1990: xi), believing that the pluralism of life leaves the philosopher unable to make these kinds of pronouncements. Instead, he builds a process though which the justification of norms can be reached.

The principle of discourse ethics (D) is:

Only those norms may claim to be valid that meet (or could meet) with the consent of all affected in their role as participants in a practical discourse (Habermas, 1990: 93).

This principle breaks with Kantian ethics in that it says that the question of "what should we do" cannot be decided monologically (that is, by an individual in isolation from those who would be affected by the norm). Instead, valid norms are produced through a process which they can "meet with the consent of all". 
This requirement is met through the principle of universalization (U), which states the condition that every valid norm must fulfill:

All affected can accept the consequences and the side effects its general observance can be anticipated to have for the satisfaction of everyone's interests (and these consequences are preferred to those of known alternative possibilities for regulation) (Habermas, 1990: 65).

For Habermas, the principle of universalization means that norms must be judged through argumentation in which those affected are constrained "to adopt the perspectives of all others in the balancing of interests" (Habermas, 1990: 65). As well, for rational discourse to take place, several presuppositions of argumentation must be assumed to be approximately met. These conditions, according to Habermas, can be distinguished across three categories: "those at the logical level of products, those at the dialectical level of procedures, and those at the rhetorical level of processes" (Habermas, 1990: 87). The conditions which are most discussed and well known are those at the process level:

3.1 Every subject with the competence to speak and act is allowed to take part in a discourse.

3.2

a. Everyone is allowed to question any assertion whatever.

b. Everyone is allowed to introduce any assertion whatever into the discourse.

c. Everyone is allowed to express his attitudes, desires and needs.

3.3 No speaker may be prevented, by internal or external coercion, from exercising his rights as laid down in (3.1) and (3.2) (Habermas, 1990: 89).

So, the conditions of rational discourse dictate that anyone may be included in the debate and that all individuals can participate equally and without coercion. Further, those that are involved do so with the intent of being swayed solely by the "unforced force of the better argument" (Habermas, 1998: 306).

The outcome, here, is that discourse ethics lays the foundation for a procedural justification of norms based on communicative action. Habermas has since applied discourse ethics in a variety of settings. He has looked at issues of medical ethics (Habermas, 2003), terrorism (Borradori, 2003) and law (Habermas, 1998). In applying his discourse ethics to law and politics, Habermas offered his version of deliberative democracy (Habermas, 1998), which we describe next.

\subsection{Deliberative democracy (1998)}

Habermas' work on deliberative democracy in Between Facts and Norms (1998) is another continuation of the foundation put in place in the Theory of Communicative Action. In many ways, it can be seen as Habermas' attempt to bridge the boundary between lifeworld and system by conceiving of a system of law that recognizes both its role in setting rules for citizens and its legitimation by citizens through democratic processes. It fulfills the project he set out for himself in the Theory of Communicative Action by seeking to "set limits to the inner dynamic of media-steered subsystems [in this case, the political system] and to subordinate them to decisions arrived at in unconstrained communication [i.e., democracy]" (McCarthy, 1984: xxxvii).

Deliberative democracy is a relatively new model of democracy, which focuses on deepening political participation in the democratic process (Held, 2006). Held says,

The major contention of deliberative democrats is to bid farewell to any notion of fixed preferences and to replace them with a learning process in and through which people come to terms with the range of issues they need to understand in order to hold a sound and reasonable political judgement (Held, 2006: 233).

Habermas' discourse ethics provides a foundation upon which this learning process can take place (Habermas, 1998). In Between Facts and Norms (1998), Habermas establishes that laws can be seen as norms (since it is norms which are decided through discourse ethics). He argues that law is "a set of coercible rules and impersonal procedures that also involves an appeal to reasons that all citizens should, at least ideally, find acceptable" (Rehg, 1998: xi). An analysis of law, therefore, must take into account the 
tension between facts - enacted and enforceable laws - and norms - law's claim to legitimacy. For Habermas, this tension is addressed by the relationship between law and democracy. Law provides a system (in the full Habermasian sense) which mediates social integration by removing the burdens of having to achieve communicative action on every issue, but only by standing in for a democratic and communicative process which has produced and delegated action to these laws. As a result, democracy provides the procedures that give law its form and legitimacy because, through the democratic process, citizens have a voice in the process on deciding upon which laws are in the collective's best interests.

The legitimacy of law stems from a guarantee of both public and private autonomy (Rehg, 1998: xxv). A system of rights must be in place to ensure both simultaneously. These rights include:

- the right to the greatest possible measure of equal individual liberties,

- the right to membership (citizenship) and the right to legal remedies if these rights are violated,

- a right to an equal opportunity to participate in the formation of public opinion and will formation toward the generation of law (Habermas, 1998: 123) and,

- the right to social welfare because the exercise of civil and political rights is contingent on basic social and material conditions for citizens.

Of particular interest is the right to participate in the formation of public opinion and will formation. This opinion and will formation must adhere to the principles of discourse ethics (i.e., the presuppositions of argumentation); without this, norms - that is, laws - will fail to be both procedurally and substantially legitimate with citizens. Consistent with deliberative democracy, Habermas is careful to stress that this is opinion and will formation. This opinion and will does not exist prior to these discussions; it is through this process that opinion and will are created (i.e., deliberative democracy's learning process).

With these rights in place, Habermas considers the role of the state. An important role of the state is to provide a police force in order to enforce the system of rights (Rehg, 1998). Further, the state has three other important roles. The first is a legislature to pass and make laws. The second is a judiciary to interpret law and to resolve conflict. The final is the administration who implements "legal programs that are not self-executing but need to be carried out" (Habermas, 1998: 186). Habermas is careful, here, to caution against an overly concrete interpretation of legislature, judiciary and administration, clarifying that the important aspects of these three independent branches are "the functions of legislation, application and implementation" (Habermas, 1998: 193).

\section{Evolutions in Habermasian thought}

Alvesson and Willmott (1992) define a utopian project as one which provides an alternate agenda, "an overall 'vision,' which avoids or minimizes current problems" (p. 450). This is indeed what Habermas offers. However, his work has been critiqued as too utopian and therefore impractical. This view is shared in information systems, with Hirschheim and Klein (1994) suggesting that the Habermasian-inspired neohumanism is "strong on utopian vision but short on principles for implementation" (p. 99). Metcalfe (2002) also explains why he did not use a Habermasian perspective in developing an IS design method:

“However, Habermas seems to be assuming a 'co-operative' discourse with no assumptions of power inequalities or one party trying to persuade the other. A more pragmatic application of argument, especially in commercial hierarchical decision-making settings, is that it needs to be structured so as to acknowledge power inequalities by making it explicit and not calling for consensus" (p. 71).

Metcalfe's critique is about the implausibility of the "ideal speech situation"; Ulrich (2001a, 2001b) critiques Habermas work on the basis of the impossibility of consensus.

However, three particular clarifications in Habermas' later thought speak to a stronger practicality for his theory. In each case - "the ideal speech situation", participation by all and the consensus ideal Habermas' more recent work has shown that, while his vision remains utopian, the Habermasian project is a practical one - to implement institutional measures to move toward that vision. Habermas' clarifications concerning practicality, along with their implications for IS research, are explored next. 


\subsection{Presuppositions of argumentation ("The Ideal Speech Situation")}

Habermas' work on discourse ethics, as explicated in Moral Consciousness and Communicative Action (1990) and Justification and Application (1993), reveals an important clarification regarding the "ideal speech situation". Habermas moves away from this term, preferring instead "the presuppositions of argumentation". He says, "unfortunately, I once dubbed the conditions under which these idealizing presuppositions would be fulfilled the 'ideal speech situation,' a term whose concretistic connotations are misleading" (Habermas, 1993: 163-4). Here, he is responding to critics who have argued against the possibility of the "ideal speech situation". However, Habermas' project is not to suggest that this idealized situation exists but, rather, to say that in order to undertake discussion, participants must assume these presuppositions have been sufficiently addressed. Re-labeling these conditions "the presuppositions of argumentation" is meant to convey this intention.

This change is much more than a simple clarification of terms. Contrary to what critics suggest, Habermas recognizes that "[d]iscourses take place in particular social contexts and are subject to the limitations of time and space" (Habermas, 1990: 92). Further, he recognizes that participants of a discourse are "real human beings driven by motives in addition to the one permitted motive of the search for truth" (ibid). Organizers of argumentation must consider these conditions and implement institutional measures to better approximate them:

Topics and contributions have to be organized. The opening, adjournment, and resumption of discussions must be arranged. Because of all these factors, institutional measures are needed to sufficiently neutralize empirical limitations and avoidable internal and external interference so that the idealized conditions always already presupposed by participants in argumentation can at least be adequately approximated (Habermas, 1990: 92).

This is an important clarification of Habermas' thinking. He does not believe that the presuppositions of argumentation represent reality: "The conditions under which arguments actually occur are clearly not the same as those of the ideal speech situation - at least not often or usually" (Habermas, 2001: 102). However, these conditions stand as "a critical standard that can also be used to call into question any factually attained consensus and to examine whether it is a sufficient indicator of real mutual understanding" (Habermas, 2001: 97). ${ }^{4}$

For researchers and practitioners interested in creating more democratic processes through or around IS, this renewed understanding directs our attention to the measures which allow the communication context to better approximate the presuppositions of argumentation. What are the conditions which constrain specific technologies from meeting their communicative potential? What are the limitations in various communicative situations and what socio-technical systems and practices might be implemented to better support this communication? For example, how do (or don't) knowledge management systems transform those who are able to speak and participate in the shaping of organizational practices? What are the limitations in various IS development and implementation settings, and what socio-technical systems and practices enable organizational dialog about practices and direction among participants?

The presuppositions of argumentation serve as a guidepost for these assessments and suggest where organizers and participants should direct their attention. For example, who is being excluded from a discussion? Is there a set of socio-technical practices that can be put in place to better approximate "participation by all"? How can participants in a discussion be better enabled in initiating discussion on topics of interest and importance to them and others? In Section 4, we show how this Habermasian perspective can be used to redesign the information systems development process to better respond to the needs and desires of those who will eventually use and are affected by information systems.

\subsection{Consensus}

Another important notion in Habermasian thought is the consensus ideal. It underpins both the presuppositions of argumentation and discourse ethics. Habermas says,

\footnotetext{
${ }^{4}$ This quote is from Habermas, 2001 but is from a reprint of Habermas, 1971 lecture entitled "Truth and Society: The Discursive Redemption of Factual Claims to Validity".
} 
This concept of communicative rationality carried with it connotations based ultimately on the central experience of the unconstrained, unifying, consensus-bringing force of argumentative speech, in which different participants overcome their merely subjective views and, owing to the mutuality of rationally motivated conviction, assure themselves of both the unity of the objective world and the intersubjectivity of their lifeworld (Habermas, 1984: 10, italics added).

However, practically speaking, consensus can be difficult to achieve especially in large groups. This has been the subject of a number of critiques of Habermas' work (cf., Warnke, 1995). Certainly when proposing a far sweeping procedurally-based democracy, Habermas is completely clear about this problem. As a result, Habermas makes room for decisions based on majority rule:

Majority rule retains an internal relation to the search for truth inasmuch as the decision reached by the majority only represents a caesura [pause] in an ongoing discussion; the decision records, so to speak, the interim result of a discursive opinion-forming process (Habermas, 1998: 179-180).

This is a critical move in Habermasian thought. While consensus remains the ultimate goal, majority rule decisions can suffice in the interim, under the strict condition that a decision can be revisited if minority positions can bring forward arguments to sway the majority at a later point in time.

In this vein, Hansen et al. (2009) analyze Wikipedia through the lens of discourse ethics to determine its emancipatory potential for communication. They find that Wikipedia approximates the conditions for Habermas' rational discourse, creating a more emancipatory context than traditional forums have allowed. This finding is dependent upon an updated understanding of the consensus ideal of Habermas. The authors recognize that Wikipedia pages do not represent a final consensus on a particular topic but rather are a temporary understanding based on the contributions so far (i.e., an "interim result of a discursive opinionforming process" (Habermas, 1998: 180)). What makes this a reasonable approximation of consensus within rational discourse is the continued and ongoing opportunity for discussion and dissent.

This renewed understanding of the consensus ideal holds implications for IS researchers and practitioners. Organizers of technologies and processes that seek to support consensus-building need to consider how interim decisions might be made and implemented, and how these decisions can be revised as discussions continue. Processes and technology for supporting these ongoing discussions must also be considered. For IS researchers, this is particularly constructive in informing the design of information systems development and information systems planning processes as well in developing and using technologies to support IS and other organizational consensus-building processes.

\subsection{Participation by all}

Given the consensus ideal, it is not surprising that another important principle in discourse ethics is participation by all. Habermas calls for this, while recognizing the challenge implicit in achieving it.

Justified and binding decisions about policies and laws demand, on the one hand, that deliberation and decision making take place face to face. On the other hand, at the level of direct and simple interactions, not all the citizens can join in the shared exercise of such a practice. A solution to this problem is provided by the parliamentary principle of establishing representative bodies for deliberation and decision-making (Habermas, 1998: 170).

He thus makes clear that, under the right conditions, a system of representation does not violate the presuppositions of argumentation which require equal participation:

All members must be able to take part in the discourse, even if not necessarily in the same way. Each must have fundamentally equal chances to take a position on all relevant contributions with a yes or no.... Discourses conducted by representatives can meet the condition of equal participation on the part of all members only if they remain porous, sensitive, and receptive to the suggestions, issues and contributions, information and arguments that flow in from a discursively structured public sphere, that is, one that is pluralistic, close to the grass roots, and relatively undisturbed by the effects of power (Habermas, 1998: 182, emphasis in original). 
In this context, representatives are generally selected in free, equal and secret elections.

Also important is the relationship of representatives to those represented; Habermas argues they must be "porous, sensitive and receptive to the suggestions ..." that flow from the public sphere. That is, representatives must be available to those that they represent so that all members can contribute to the discussion process.

As the organizational footprint of information systems has grown, the challenge of creating strong communicative processes around and about technology has also grown. Even when desirable, involving all affected in these discussions has become increasingly difficult; the Habermasian goal of "participation by all" appeared impossible. With this clarification in Habermas' thinking, however, IS researchers and practitioners need to focus greater attention on representation processes and structures. Who are the representatives? How are they selected? Who are the constituents? How is communication between constituent and representative supported? Further, what practices and technologies can support this representation process? While many IS processes such as those related to IS planning and development already depend upon representation, achieving representation that meets Habermas' democratic ideal requires paying particular attention to these questions.

\section{Applying Habermas to is research: a reconceptualization of the requirements process}

All three of these clarifications - to the presuppositions of argumentation, the consensus ideal and participation by all - are important because they are Habermas' response to critiques of his work. Habermas is showing, in these changes, that his work is not simply an idealistic, utopian and therefore impossible vision. It can be brought to bear in real world situations, making Habermas' theoretical perspectives amenable to empirical IS research. We have already highlighted some possible implications of this for IS research; in this section, we provide a more detailed example.

The requirements process in information systems development is an important and illustrative area in which discourse ethics and deliberative democracy can provide important directions for practice and future research. Requirements determination is the process by which the desired capabilities and outcomes of a new and proposed information and technology are gathered, defined and documented. This process is arguably the most influential part of the delivered information system and is widely seen to be the most complex activity in information systems development (Browne \& Rogich, 2001).

Researchers have attributed many system development "failures" to inadequate or incorrect requirements (c.f. Alvarez \& Urla, 2001; Vessey \& Conger, 1994). Research has provided some insights into these failures, identifying such things as language translation between technical and functional experts (Browne \& Ramesh, 2002; Williams \& Begg, 1993), human cognitive limitations (Browne \& Ramesh, 2002; Stacy \& MacMillian, 1995; Vessey \& Conger, 1994), the complexity of the process (Browne \& Ramesh, 2002) as well as methodological problems (Browne \& Rogich, 2001; Ocker, Fjermestad, Hiltz, \& Johnson, 1998). Yet, despite these insights, significant problems remain (Lindquist, 2005).

At the heart of the requirements process, especially for information systems that affect the interaction among their stakeholders, is the need to reach a shared understanding about the functionality that will be provided in the proposed system (Urquhart, 1997), in order to provide a basis for collective action. Habermas' work, with its focus on communication, mutual understanding and coordination of action, is particularly well suited to supporting this endeavor.

Habermas work has been applied to both the requirements process and to the participation upon which much of the requirements process is based. Hirschheim and Klein (1994) demonstrate that Mumford's ETHICS, an important and participatory development method, could serve Habermas' emancipatory goal, arguing that this was important for information systems development: "Neohumanism can suggest how to see old issues in a new light and tackle many unresolved problems of ISD in a novel way" (p. 83). Further, they say, "Such a treatment of emancipatory concerns is important because it could contribute to the realization of democratic ideals at the organizational level" (p. 84). Ulrich (2001a, 2001b) offers critically systemic discourse, also based in Habermasian thought, as an approach to information systems development practice. Auramäki et al. (1988) offer SAMPO (Speech-Act-based office Modeling aPprOach) as another. The Theory of Communicative Action has also been used to build a framework of the intellectual structures in the information systems development field (Hirschheim et al., 1996). 
However, all of these offerings draw upon Habermas' earlier work. The clarifications and additional thought offered in his later works provide an opportunity to refine and extend Habermasian approaches to information systems development. In particular, the system of law and democracy provided by Habermas serves as a critical and important theory on the requirements process that suggests revisions to requirements determination activities. Jones, Mason, and Stamper (1979) applied a legal analogy to create a system specification language so the application of law in information systems development is not new. The basic premise of our argument is that, if we can treat requirements as though they were like laws, then Habermas' deliberative democracy can provide important insights into how requirements should be created and applied.

\subsection{Assumptions of a Habermas-inspired requirements process}

To be able to apply the ideas contained in deliberative democracy to the requirements process, we must first establish the possibility of such an endeavor. A first question is whether it is possible to apply Habermas' societal-level concepts in an organizational context. We deal with the questions this raises in Section 4.1.1. The second question is whether we can adequately draw a parallel between requirements and laws, as this forms the basis upon which we seek to apply the theory. This is dealt with in Section 4.1.2.

\subsubsection{Organizations as sites of communicative action}

An important question that must be answered before we proceed with proposing a Habermas-inspired requirements process is whether it is possible to apply Habermas' theory in organizations, which appear to be structured against communicative action through hierarchical organization and an orientation toward the achievement of predefined goals. That is, can we really expect an organization to employ the democratic principles of Habermas?

The problem here is that, as part of the economic system, organizations are generally seen as sites of strategic and instrumental action. This is appropriate, from a Habermasian perspective, because the economic and administrative subsystems arose in order to remove the communicative burden that would otherwise be associated with seeking mutual understanding on every issue that arises in the lifeworld; they are, therefore, appropriately associated with strategic and instrumental action. However, work and workers in an organization straddle both the lifeworld and system:

On the one hand, labor power is expended in concrete actions and cooperative relationships; on the other hand, it is absorbed as an abstract performance by a labor process that is formally organized for purposes of valorization. In this respect, the labor power sold by producers is the site of an encounter between the imperatives of system integration and those of social integration: as an action it belongs to the lifeworld of the producers, as a performance to the functional nexus of the capitalist enterprise and of the economic system as a whole (Habermas, 1987: 335).

Therefore, "concrete actions and cooperative relationships" are the means through which labor power is realized in organizations and these belong to the lifeworld ("...as an action it belongs to the lifeworld of the producers..."). As a result, communicative action has an important role in organizations in bringing together the concerns and needs of many stakeholders, including labor, producers and customers. The challenge, of course, is that, in the organization, the struggle between strategic and communicative action is strong; strategic action, driven by systems largely outside the organization and its stakeholders' lifeworlds appears to have primacy. In response, Introna (1996) comments:

... we can offer local resistance by opting for Habermas' communicative action and rational discourse in spite of the space of strategic action that encircle us (Introna, 1996: 96).

Therefore, not only does communicative action have a role in the organization, it is necessary to ensure that the strategic and instrumental action which characterize the economic and market-based systems do not undermine and colonize the lifeworld of the stakeholders inside and beyond.

A related question is whether it is appropriate to apply the societal-level concepts of deliberative democracy to an organizational context. We recognize the challenges that this might pose, despite the long 
and productive tradition of doing so in IS research (Hirschheim \& Klein, 1994; Janson et al., 1993; Myers \& Young, 1997). Some concepts, such as communicative action, apply relatively easily because they occur at the level of the interaction. But others, especially related to deliberative democracy, may not translate as readily to the organizational context. Are individuals in organizations treated like citizens? Can we accurately talk about the functions of legislation, application and administration in an organizational context? However, our intent is not to hold these contexts to be identical but rather to use the analogy to generate important insights on our understanding of the requirements process context.

\subsubsection{Drawing a parallel between requirements and laws}

A second area that must be addressed before we can propose a model for a Habermasian-inspired requirements process is whether the parallel between laws and requirements is sufficiently strong to enable the analogy. Recall that laws can be seen as "a set of coercible rules and impersonal procedures that also involves an appeal to reasons that all citizens should, at least ideally, find acceptable" (Rehg, 1998: xi).

Requirements define the set of functions in, and procedures that surround, a new system. Once institutionalized in the system, these functions and procedures become fact-like - "coercible rules and impersonal procedures" - seemingly removed from the process through which they were decided but which govern (with some discretion) how individuals work and interact with others in the organization through various systems.

At the same time, requirements can only act in this way if they are seen to be legitimate by most people; otherwise, individuals will reject them. It might be argued that this normative view of requirements overstates the extent to which they represent the subjective world. Hirschheim et al. (1996) suggest that a control orientation of requirements sees requirements as finding the optimal fit between the information system and organization needs. In this view, requirements are more about the objective world. However, we argue that even apparent material and objective constraints are constructed as such; there is a process through which these constraints are intersubjectively determined to be appropriate and relevant to the information systems development. As a result, we argue that they retain a normative character. Therefore, requirements, like laws, are experienced as both facts (which control behavior) and norms (to which people have agreed to coordinate their actions for the collective good).

\subsection{The conditions of the Habermas-inspired requirements process model}

Having established that we can adequately apply deliberative democracy in the organizational context, our next move is to establish the important conditions under which such a view of requirements process must be based. Four important, and related, conditions must be satisfied - participation by all, time and space for opinion formation, time and space for will formation and separating legislation, application and implementation. Each of these is discussed next.

\subsubsection{Participation by all}

The first important criterion of a Habermas-inspired requirements process is that it must provide an equal opportunity for all who are affected by an information system to participate in the requirements process. Despite the obvious challenges this entails, ensuring wide participation is important because the many needs and interests of all stakeholders must have an opportunity to sway the requirements which shape their lifeworld; without this, the requirements determination process will lead to systems which do not support the individual and collective needs of many stakeholders, including workers (and in the case of Mumford's ETHICS, management). As well, without this opportunity for self-determination, the requirements will fail to hold legitimacy with those affected by the system, leading to increased resistance to the system implementation.

This resistance is even more understandable and legitimate given Habermas' vision of deliberative democracy. Based on this vision, much of what occurs during the requirements process should be about opinion and will formation - that is, the development of an understanding of, and the creation of meaning about the organization and its goals and processes for achieving these goals, supported by new systems. However, those excluded from the requirements process (typically most people in the organization especially given the criterion of "participation by all") go through a different sense-making process than those who are involved. They often will not have the same understanding of the system's purpose and 
genesis, and the various individual and collective needs and interests that are to be met through its design. As a result, the new system may appear confusing and nonsensical. This may explain why these excluded individuals experience the software in a much different and typically negative way.

For the requirements process, this criterion of "participation by all" is a critical but under-theorized and under-practiced process in organizations. Instead, the literature around this issue focuses on technical expertise and cooperation, in suggesting that managers "choose the best and the brightest" for system development participation (Finney \& Corbett, 2007). Strategically, this rationale reinforces the choosing of those who are anticipated to be the most supportive of the project. However, by definition, this marginalizes the numerous voices necessary for collective will formation and communicative action, and thus minimizes the process and outcomes.

Our understanding of "participation by all", however, has changed through the evolution of Habermas' work. Representative structures which allow all to participate need consideration. Selecting representatives and constituents becomes very important in this endeavor. Arguably the most under-theorized aspect of using representation to meet the "participation by all" requirement is ensuring a strong mechanism of communication between representative and constituent.

\subsubsection{Time and space for opinion formation}

Another important part of a Habermas-inspired requirements process is time for opinion formation. Habermas stresses the need for discussion and argumentation to ensure participants are aware of the issues and implications of discussion topics. The various needs, interests and opinions of all interested parties must be discussed in a public forum so that others may debate, challenge and consider each other's perspectives.

There are several elements that need to be included to ensure this time for opinion formation exists. First is the need to ensure that training and education towards participation and discussion are provided to participants so that they have the knowledge to participate. In general, training remains neglected in many software implementations (Bradley \& Lee, 2007), and the type of general and technical training required for a larger number of participants in will formation places a large and important onus on those initially responsible for the project.

Second, there is the need to provide an open and equal discussion forum for everyone. Given the traditional and hierarchical approach to organizational systems, the need to be concerned with understanding the organizational and historical relations of power in a particular context and the need to put in place appropriate institutional measures to encourage debate and dialog across the many marginalized voices is admittedly difficult but paramount.

Third is the requirement for communicative forums that allow informal spaces for "free-floating opinions, validity claims, and considered judgments" (Habermas, 1998: 171). In the legal case in Between Facts and Norms, Habermas (1998) defines this public sphere as consisting of "an intermediary structure between the political systems, on the one hand, and the private sectors of the lifeworld and functional systems, on the other." (p. 373). It is here that various publics discuss and debate issues of importance to them and here that opinions are formed and re-formed, shared and debated. In the legal case, the mass media clearly play an important role in this public sphere. Habermas says:

...the mass media ought to understand themselves as the mandatary ${ }^{5}$ of an enlightened public whose willingness to learn and capacity for criticism they at once presuppose, demand and reinforce; like judiciary, they ought to preserve their independence from political and social pressure; they ought to be receptive to the public's concerns and proposals, take up these issues and contributions impartially, augment criticisms, and confront the political process with articulate demands for legitimation (Habermas, 1998: 379).

Obviously this element of our analogy does not fully translate to the organizational context. However, we can still consider the implications of this requirement for systems development and the requirements process? To allow opinion formation among the broader organization, communication and dialog from the project team to the rest of the organization is required. In one project in which the first author was

\footnotetext{
${ }^{5}$ Mandatary: the recipient of a mandate (http://www.thefreedictionary.com).
} 
involved, a project manager talked about needing to "come out of the cave" - that is, needing to provide more outward communication (from the project team to the rest of the organization) (reference blinded). However, their concern - one we believe is dominant in many projects - was that an instrumental motivation to avoid sharing information about the system before it has been made pristine and error proof may have created fear and anxiety. The problem with this strategic intent is that it effectively cuts off opinion formation for the most of the organization during the early stages of system development projects, and moves towards the presentation of a finalized and completed software artifact; hardly a space for will formation and participation by all.

This suggests that, while organizations do not have access to an independent mass media, creating strong outward communications and spaces for opinion formation remains important. Considering how to minimize the impact of organizational power relations within this forum is also necessary.

\subsubsection{Time and space for will formation}

Often, opinion and will formation are spoken together as though they are one and the same. Clearly, they are highly related but will formation speaks most clearly to the decision-making process. As we have seen, Habermas is often associated with decision-making through consensus. However, he recognizes that it can be impractical to include all participants in a consensus-seeking process: "[o]n the other hand, at the level of direct and simple interactions, not all the citizens can join in the shared exercise of such a practice" (Habermas, 1998: 170). Instead, as we have seen, he offers the use of majority rule decisions. These decisions can still approximate communicative action if they can be revisited.

This has important implications for a Habermas-inspired requirements process. It means that an organization does not have to seek consensus amongst all participants; majority rule can suffice. However, majority rule requires that any vote-based decision is at best an interim decision that leaves open the possibility of further argumentation and challenge.

A Habermas-inspired requirements process, then, must make room for majority rule decisions to be revisited, reconsidered and overturned by new agreements. This has significant impacts on information systems development which have to handle changing requirements. Adaptive and iterative processes may be best suited to this type of approach. Note, as well, that this change in the requirements process has implications on the systems that are created as well. When requirements decisions are seen as interim, more system changes might be expected and, therefore, flexible systems will be required to handle ongoing and possibly more frequent changes.

\subsubsection{Separating legislation, application and implementation}

In Habermas' view of the state, three important functions of government were identified - legislation (legislative branch), application (judiciary) and implementation (administrative branch). Habermas argues that these functions necessarily represent different types of discourse and participants, and they should remain separate. The discourse of legislation is one undertaken by participants and represents a process of public opinion and will formation. The discourse of implementation brings in questions of efficiency (Flynn, 2004). The discourse of application is used to decide how to apply applicable laws in specific situations and on the penalties that should be applied when laws are violated. Attempting to jointly undertake these discourses violates the presuppositions of argumentation. For example, the discourse of legislation (oriented toward mutual understanding and coordination of action) would be undermined by discussions of implementation efficiency. Further, since the judiciary (responsible for the function of application) is responsible for sanctions; keeping the application function separate from the other discourses reduces the external coercion to which these other discourses may be subject.

In drawing the parallel from Habermas' reconstruction of the legal system to the requirements process, the discussion so far has focussed on legislation (i.e., the requirements-making process) but it is also important to consider how requirements, as "coercible rules and impersonal procedures" (Rehg, 1998: xi), are implemented and enforced. Implementation of the requirements is undertaken by the project team during system development and implementation. The "administrative branch" of software development is therefore the project team, which leads the implementation.

The judiciary in this requirements reconstruction is most clearly management. How individuals incorporate a system into their daily work lives is an emergent property of the technology, the individual and the organizational context (Orlikowski, 1992) and may not be authentic to the original requirements. 
Management has a role in enforcement, then, through the extent to which they choose to mandate system use. These organization roles are summarized in Table 2.

As has been discussed, Habermas calls for the separation of powers among these branches. Particularly important from the perspective of systems development is the separation of powers between the legislative process (i.e., the requirements process) and administrative function (i.e., the development and implementation processes). Habermas (1998) says, "These normative reasons belong to a universe in which legislature and judiciary share the work of justifying and applying norms. An administration limited to pragmatic discourses must not change anything in this universe by its contributions." (p. 192). In many projects, the legislative and administrative functions are both led by a single project team, making it difficult to keep implementation issues from colonizing requirements formation because the project team is simultaneously responsible for meeting time and cost project constraints while leading requirements formation. Supporting more democratic communication requires mechanisms to ensure this colonization does not occur.

One method for achieving this is to have distinct requirements and implementation teams but this reveals a certain tension in this reconstruction. Requirements have been cast as norms, which emerge and gain legitimacy through the requirements process. Yet, requirements also have technical implications. A complete separation of the requirements and implementation teams could make it difficult for developers and analysts to bring these technical concerns to the discussion. However, separation does not mean excluding developers and analysts from the requirements process. In describing Beck's (1996) move to democratize science along deliberative democratic lines, Ekberg (2007) says, "Accordingly, the democratization of science does not exclude experts, rather it combines experts and non-experts in a cooperative and communicative framework." (p. 359). In this same vein, we would argue that a separation of requirements and implementation does not exclude implementation concerns from the will formation process. In fact, IS researchers and practitioners are keenly aware that technical, social and implementation concerns need inclusion in the IS development process (Mumford, 1983). The separation of requirements and implementation teams simply creates a more formal and clear demarcation of implementation concerns so that they can be properly identified and prioritized as such. This allows, therefore, the implementation team to bring their concerns into the requirements formation process without allowing these concerns to cut off opinion and will formation.

Achieving this goal may also take alternate forms. The separation of requirements and implementation teams may be replaced, or supported by, other checks and balances and, of course, dialog to ensure this same end. For instance, in agile development and prototyping methods, requirements discovery and implementation are more closely intertwined so a complete separation of requirements and implementation may not be possible. Yet, in these types of methods, signoff processes between iterations are the norm so it is in this space that requirements organizers can ensure a separation of requirements and implementation and ensure that discussion of the current software iteration properly prioritizes implementation concerns along all others.

\subsection{Applying the Habermasian-inspired conditions to ETHICS}

We have proposed here a Habermasian-inspired requirements process that sees the process not as a search for truth but instead as a time of will formation. In doing so, we have not set out the exact process that must be followed; this, in fact, would be counterproductive to Habermas' emancipatory project. Instead, we have provided the conditions that would be necessary to implement such a project. In this final section, we apply these conditions to Mumford's ETHICS, a well studied and explored IS development

Table 2

Necessary branches of the requirements process.

\begin{tabular}{lll}
\hline Branches & Function & Fulfilled by \\
\hline Legislative & Legislation (Requirements are discussed and decided) & Requirements process \\
Administrative & Implementation (Requirements are implemented) & Project team \\
Judiciary & Application (Decisions about how to apply the software are made) & Management \\
\hline
\end{tabular}


method, in order to demonstrate the productive changes made possible through this new understanding of Habermas' work.

Hirschheim and Klein (1994) argue that Mumford's ETHICS, an information systems development method based heavily on participation, is one method through which emancipatory principles can be realized. They suggest that ETHICS' focus on dialectical inquiry, inclusion of a broad range of interests, bringing conflicts into the open, equalization of power distribution and provision of a steering group and facilitator to mediate disputes help to satisfy the conditions necessary for rational discourse as laid out by Habermas. Further, they argue that ETHICS allows for:

- the realization of technical concerns by making room for efficiency and effectiveness without privileging them over social concerns;

- the realization of communicative concerns through homogeneous groups to minimize power concerns, small member groups for face-to-face discussion, the institutionalization of synthesis and compromise (favoring compromise, oriented toward consensus) and a facilitator to remove barriers to communication; - the realization of emancipatory concerns through participation.

While ETHICS is more than just a requirements process, it meets the conditions of our Habermasianinspired requirements process through its focus on representation, with a concern for strong connections between representatives and constituents, and its concern for implementing institutional measures to move the participatory experience closer to meeting the presuppositions of argumentation.

As suggested by our conditions of a Habermasian-inspired requirements process, ETHICS provides for the separation of technical and social concerns (Hirschheim \& Klein, 1994). Doing this allows social issues to be discussed without being overwhelmed by technical issues. Results from the social and technical subgroups are brought together in later meetings. This is in the spirit of separating legislation and implementation. However, by completely separating the groups early on, there is little opportunity for all to appreciate the social and technical concerns throughout the process. Developing a process that separates the teams but allows both into the opinion and will formation process would ensure a stronger requirements process.

The conditions of our Habermasian-inspired requirements reveal two important other areas not addressed in ETHICS. First, it does not consider the critical issue of time for opinion and will formation. While Mumford calls the process a "shared learning process", by focusing on questionnaires from participation to designer, homogeneous groups and small group meetings, there is little time for participants to develop interests and opinions through discussion with others. Hearing dissenting opinions and questioning others is an important part of the opinion formation process that is circumvented in these types of communication forums.

Further, ETHICS offers a facilitator and steering committee as the means by which contentious issues are resolved. When consensus is viewed as the only appropriate way of making decisions, concerns about the efficiency of argumentation arise; discussion cannot always continue until all agree on a single course of action. Some means of moving past contentious issues is required. In ETHICS, the facilitator and steering committee are seen to provide this. This, however, gives ultimate power to the facilitator and steering committee, undermining the equality of power ETHICS seeks otherwise to put in place. As we have shown, however, Habermas provides other options, allowing majority rule, or possible other decision-making processes, with the provision that decisions made in this way can continue to be revisited.

Originally, Mumford (1983) and increasing technical competence of workers. When these power bases were eroded, she argued that management would see worker empowerment and involvement as important to collective success. This also failed to materialize, prompting her later commentary that ETHICS appears to have been largely unrealized in organizational practice (Mumford, 2006). Habermas, in his idealism, argues that the democratic appeal of "more heads are better than one", and the quest for rationally argued and debated mutual understanding and coordination of action is itself a universally valid argument that can be won in society as well as in organizations. The foundation of his theory of democracy thus remains both idealistic and beyond the erosion of particular conditions, and thus fosters a broad reconsideration of the foundation for user participation in systems development.

\section{Conclusion}

Habermas'Theory of Communicative Action has played an important role in Information Systems research over the past twenty-five years. Since this important work was published, Habermas has revised 
and clarified his ideas through important contributions on discourse ethics and deliberative democracy. Our objectives in this paper were to explore these clarifications and extensions in order to understand the opportunities they present for IS research.

Our contributions are several. First, we have identified and explained three important changes in the empirical practicality of Habermas' theory. The presuppositions of argumentation, participation by all and the consensus ideal remain utopian ideals that serve as a guide to stronger communication. Nevertheless, through his more recent work, Habermas has revealed these ideals to be more practical than they first appeared in his early work. These changes renew the possibilities for applying Habermas' theory in IS research. What are the limitations in various communicative situations and what socio-technical systems and practices might be implemented to better support this communication? This updated understanding makes it possible to talk about the institutional measures that might be taken to move various contexts toward the ideal of communicative action, even while we recognize that we cannot ever fully achieve it.

Second, we have increased the possible breadth of Habermasian theory that IS researchers might apply. As demonstrated in our requirements process example, discourse ethics and deliberative democracy provide related but new perspectives for understanding IS phenomena. Perhaps most critical about this work for IS research is the importance of opinion and will formation. Understanding how to support this ongoing communication through processes and technology is an important open question for IS researchers and practitioners.

Third, this updated understanding of Habermas' work allowed us to consider how the requirements process can be made more democratic. First, participation by all must be taken very seriously in the requirements process, especially in including people outside the project team. Second, the requirements process must be seen as an important time for opinion and will formation in which an equal opportunity for participation is paramount. Critical here is to support and allow a public sphere which allows for opinion formation "outside the cave". This will require projects to have earlier and more ample communication across numerous, if not all, participants in the organization. Third, the requirements process can never be finished - but only finished for now. It is an on-going dialog that precedes and proceeds throughout an IS/IT project. This has important implications for projects and for organizations. As a part of this, organizations will need to roll out changes to software and information systems practices more frequently, to learn from the unintended effects of systems implementations, and to increase dialog and support for this continuous process.

The changes necessary to implement this type of process will not come easily in organizations, which sit, uncomfortably at times, at the intersection of the strategic economic system and the communicative lifeworld, where strategic action confronts and often dominates communicative action. A particular challenge will be that the assumptions on which these suggestions rest will be foreign to many participants. Requirements as norms and as a social process are not the way many companies and project participants envision system development and requirements determination. However, the importance of moving toward a process more firmly based in a deliberative democratic model seems clear from a Habermasian viewpoint; the entire legitimacy of the requirements process is otherwise at issue.

Future research will help to understand the bounds of this Habermasian reconstruction. Its emphasis on requirements as norms makes it most clearly relevant with information systems which impact multiple and identifiable stakeholders in ways that affect their interaction. Requirements for infrastructure projects, for example, which are implemented with fewer impacts on how stakeholders work, act or live together, are less likely to be seen as norms. This reconceptualization may not apply to projects of this nature. Action research for studying the extent to which this perspective on requirements applies in various contexts would help establish this boundary.

It must be noted that we have not exhausted the ways in which Habermasian theory has evolved. Mingers (2008) has already discussed important changes in the way Habermas conceives of truth. As well, Habermas' view of power has changed substantially from a force that allows a person in power to "condition the responses of those subordinate to him, without having to depend primarily on their willingness to cooperate" (Habermas, 1987: 268) to include a more productive view of communicative power through which a shared will can be created and through which this shared will can be implemented as enforceable law (Habermas, 1998). While there is not room here to explore these changes in depth, they represent other important changes for IS researchers interested in Habermasian theory.

Despite these changes, which are largely in response to Habermas' engagement with his critics, we concede that many will still find limitations and problems with his work. He is still a theorist grounded in 
the ideal of rational discourse, despite acknowledging and providing methods of dealing with practical situations. He still proposes a view of communication on which the ultimate goal (however unattainable) is to minimize the external forces that undermine mutual understanding. These are positions which many, both functionalists and poststructuralist philosophers alike, will find difficult to accept.

Nevertheless, for others, the changes in Habermas' theoretical positions will be important. As demonstrated in our Habermasian reconceptualization of the requirements process and as evidenced by more recent IS research (Asif \& Klein, 2009; Hansen et al., 2009; Mingers \& Walsham, 2010), Habermas' work is more amenable to empirical research and pragmatic application than many have believed. This opens a large space for new investigations and understandings about information systems and the processes that surround their creation, management and use. However, this promise can only be fulfilled as IS researchers (and their editors and reviewers) recognize that Habermasian thought has evolved - in many ways, substantially - since the Theory of Communicative Action. Casting new light on participation by all, the presuppositions of argumentation and the consensus ideal and reconsidering the requirements process in this new light are our contributions to this goal.

\section{References}

Adam, A. (2002). Exploring the gender question in critical information systems. Journal of Information Technology, 17, 59-67.

Alvarez, R., \& Urla, J. (2001). Tell me a good story: Using narrative analysis to examine information requirements interviews during an ERP implementation. Data Base, 33(1), 38-52.

Alvesson, M., \& Willmott, H. (1992). On the idea of emancipation in management and organization studies. Academy of Management Review, 17(3), 432-464.

Asif, Z., \& Klein, H. K. (2009). Open and free deliberation: a prerequisite for positive deliberation. Information and Organization, 19, $186-197$.

Auramäki, E., Lehtinen, E., \& Lyytinen, K. (1988). A speech-act-based office modeling approach. ACM Transactions on Office Information Systems, 6(2), 126-152.

Austin, J. L. (1962). How to do things with words: The William James Lectures delivered at Harvard University in 1955. Cambridge, MA: Harvard University Press.

Beck, U. (1996). The reinvention of politics: Rethinking modernity in the global social order. Cambridge: Polity Press.

Borradori, G. (2003). Philosophy in a time of terror: Dialogues with Jürgen Habermas and Jacques Derrida. Chicago: The University of Chicago Press.

Bradley, J., \& Lee, C. C. (2007). ERP training and user satisfaction: A case study. International Journal of Enterprise Information Systems, 3(4), $33-49$.

Brooke, C. (2002). What does it mean to be 'critical' in IS research? Journal of Information Technology, 17, 49-57.

Browne, G. J., \& Ramesh, V. (2002). Improving information requirements determination: A cognitive perspective. Information and Management, 39, 625-645.

Browne, G. J., \& Rogich, M. B. (2001). An empirical investigation of user requirements elicitation: Comparing the effectiveness of prompting techniques. Journal of Management Information Systems, 17(4), 223-249.

Cukier, W., Ngwenyama, O., Bauer, R., \& Middleton, C. (2009). A critical analysis of media discourse on information technology: Preliminary results of a proposed method for critical discourse analysis. Information Systems Journal, 18, 175-196.

Doan, A., Ramakrishnan, R., \& Halevy, A. Y. (2011). Crowdsourcing systems on the World-Wide Web. Communications of the ACM, 54(4), 86-96.

Ekberg, M. (2007). The parameters of the risk society: A review and exploration. Current Sociology, 55(3), 343-366.

Finney, S., \& Corbett, M. (2007). ERP implementation: A compilation and analysis of critical success factors. Business Process Management Journal, 13(3), 329-347.

Flynn, J. (2004). Communicative power in Habermas's theory of democracy. European Journal of Political Theory, 3(4), $433-454$.

Habermas, J. (1971). Knowledge and human interests. (J. J. Shapiro, Trans.). Boston, MA: Beacon [German, 1968b].

Habermas, J. (1976). What is universal pragmatics? In M. Cooke (Ed.), On the pragmatics of communication (pp. 1998). Cambridge, MA: MIT Press.

Habermas, J. (1984). The theory of communicative action. (T. McCarthy, Trans.). Volume 1: Reason and the rationalization of society. Boston, Massachusetts: Beacon Press [German, 1981].

Habermas, J. (1987). The theory of communicative action. (T. McCarthy, Trans.). Volume 2: Lifeworld and system, a critique of functionalist reason. Boston, Massachusetts: Beacon Press [German, 1981].

Habermas, J. (1990). Moral consciousness and communicative action. (C. Lenhardt, \& W. Nicholsen, Trans.). Cambridge, MA: The MIT Press [German, 1983].

Habermas, J. (1993). Justification and application: remarks on discourse ethics. (C. Cronin, Trans.). Cambridge, MA: MIT Press [German, 1991].

Habermas, J. (1998). Between facts and norms: Contributions to a discourse theory of law and democracy. (W. Rehg, Trans.). Cambridge, MA: The MIT Press [German, 1992].

Habermas, J. (2001). On the pragmatics of social interaction: Preliminary studies in the theory of communicative action. (B. Fultner, Trans.). Cambridge, MA: The MIT Press.

Habermas, J. (2003). The future of human nature. (H. Beister, M. Pensky, \& W. Rehg, Trans). Cambridge: Polity Press.

Hansen, S., Berente, N., \& Lyytinen, K. (2009). Wikipedia, critical social theory, and the possibility of rational discourse. The Information Society, 25(1), 38-59.

Held, D. (2006). Models of democracy (3rd edition). Stanford, CA: Stanford University Press.

Hirschheim, R., \& Klein, H. K. (1994, Marchh). Realizing emancipatory principles in information systems development: The case for ETHICS. MIS Quarterly, 83-109.

Hirschheim, R., Klein, H. K., \& Lyytinen, K. (1996). Exploring the intellectual structures of information systems development: A social action theoretic analysis. Accounting, Management and Information Technology, 6(1/2), 1-64.

Horster, D. (1992). Habermas: An introduction. (H. Thompson, Trans.). Philadelphia: Pennbridge Books. 
Introna, L. (1996). Commentary on the intellectual structures of information systems development by Hirschheim, Klein and Lyytinen. Accounting, Management and Information Technology, 6(1/2), 87-97.

Janson, M. A., Woo, C. C., \& Smith, L. D. (1993). Information systems development and communicative action theory. Information and Management, 25, 59-72.

Jones, S., Mason, P., \& Stamper, R. (1979). LEGOL 2.0: A relational specification language for complex rules. Information Systems, 4, $293-305$.

Lindquist, C. (2005). Required: Fixing the requirements mess. CIO, 19(4), 1.

McCarthy, T. (1984). Translator's introduction in Habermas. The Theory of Communicative Action, 1, McCarthy, T. (trans).

McCarthy, T. (1990). Introduction in Habermas. Moral Consciousness and Communicative Action. Lenhardt, C. and Nicholsen, S. W. (trans).

Metcalfe, M. (2002). Argumentative systems for IS design. Information Technology and People, 15(1), 60-73.

Mingers, J. (2008). Management knowledge and knowledge management: realism and forms of truth. Knowledge Management Research \& Practice, 6, 62-76.

Mingers, J., \& Walsham, G. (2010). Toward ethical information systems: The contribution of discourse ethics. Management Information Systems Quarterly, 34(4), 833-854.

Mumford, E. (1983). Designing human systems for new technology - The ETHICS method. Retrieved July 11, 2006 from. http://www. enid.u-net.com/C1book1.htm.

Mumford, E. (2006). The story of socio-technical design: Reflections on its successes, failures and potential. Information Systems Journal, 16, 317-342.

Myers, M. D., \& Young, L. W. (1997). Hidden agendas, power and managerial assumptions in information systems development: An Ethnographic study. Information Technology and People, 10(3), 224-240.

Ngwenyama, O. K., \& Lee, A. S. (1997). Communication richness in electronic mail: Critical social theory and the contextuality of meaning. Management Information Systems Quarterly, 21(2), 145-167.

Ocker, R., Fjermestad, J., Hiltz, S. R., \& Johnson, K. (1998). Effects of four modes of group communication on the outcomes of software requirements determination. Journal of Management Information Systems, 15(1), 99-118.

Olphert, W., \& Damodaran, L. (2007). Citizen participation and engagement in the design of e-Government services: The missing link in effective ICT design and delivery. Journal of the Association of Information Systems, 8(9), 491-507.

Orlikowski, W. (1992). The duality of technology: Rethinking the concept of technology in organizations. Organization Science, 3(3), 398-427.

Parmar, V., Keyson, D., \& de Bont, C. (2009). Persuasive technology to shape social beliefs: A case of persuasive health information systems for rural women in India. Communications of the AIS, 24, 427-454.

Puri, S. K., Sahay, S., \& Lewis, J. (2009). Building participatory HIS networks: A case study from Kerala, India. Information and Organization, 19, 63-83.

Rehg, W. (1998). Translator's introduction. In J. Habermas (Ed.), Between facts and norms: Contributions to a discourse theory of law and democracy. Cambridge, MA: The MIT Press (W. Rehg, Trans).

Searle, J. R. (1969). Speech acts: An essay in the philosophy of language. Cambridge: Cambridge University Press.

Stacy, W., \& MacMillian, J. (1995). Cognitive bias in software engineering. Communications of the ACM, 38(6), 57.

Ulrich, W. (2001a). A philosophical staircase for information systems definition, design, and development: A discursive approach to reflective practice in ISD (Part 1). Journal of Information Technology Theory and Application, 3(3), 55-84.

Ulrich, W. (2001b). Critically systemic discourse: A discursive approach to reflective practice in ISD (Part 2). Journal of Information Technology Theory and Application, 3(3), 85-106.

Urquhart, C. (1997). Exploring analyst-client communication: Using grounded theory techniques to investigate interaction in information requirements gathering. In A. S. Lee, J. Liebenau, \& J. I. DeGross (Eds.), Information systems and qualitative research. London: Chapman \& Hall.

Vessey, I., \& Conger, S. A. (1994). Requirements specification: Learning object, process and data methodologies. Communications of the ACM, 37(5), 102-113.

Warnke, G. (1995). Discourse ethics and feminist dilemmas of difference. In J. Meehan (Ed.), Feminists read Habermas: Gendering the subject of discourse. New York: Routledge.

Williams, M. G., \& Begg, V. (1993). Translation between software designers and users. Communications of the ACM, 36(4), $102-103$. 